REVISTA CHILENA DE LITERATURA

Noviembre 2008, Número 73, 253 - 257

\title{
EL VALLE PIERDE SU ATMÓSFERA ${ }^{1}$
}

\author{
Naín Nómez \\ Universidad de Santiago \\ nnomez@usach.cl
}

Debo empezar por señalar la grata impresión que me ha producido la publicación de esta edición crítica de la obra poética completa de Winétt de Rokha. Más que grata, me parece admirable. Desde la monumentalidad de la apariencia del libro en ese formato rokhiano un tanto desmesurado con esas letras de molde enormes, pasando por la cantidad de páginas (626), el papel grueso y brillante (tal vez excesivamente grueso), la integración de estudios críticos coetáneos y actuales, el desborde de los textos poéticos, notas, poemas de Pablo de Rokha, cartas, postales y una iconografía profusa, todo lo cual nos recuerda la objetualidad específica y definida de los propios libros de la poeta y de su marido. Se trata de una obra valiosa en muchos sentidos, pero aquí solo quiero destacar dos: 1. El rescate de una poeta, otra u otro más, olvidada, reprimida, invisibilizada, desaparecida de la tradición literaria nacional y, de más está decir, de la latinoamericana. Esto tal vez, se puede indicar de muchos escritores, ya que el panteón de la sacralización es siempre patrimonio de unos pocos elegidos o de los mejores "lobbystas", pero creo que en el caso de Luisa Winétt, el rescate tiene una importancia más que simbólica, debido a las circunstancias que rodearon su vida y su obra. La figura epigonal de su marido Pablo de Rokha en el ámbito de las vanguardias chilenas y latinoamericanas opacó su figura no solo por su propia obra monumental, sino también porque el nombre de Winétt se asoció siempre al del poeta, a lo que habría que agregar el hecho de que si bien Pablo apoyó a Winétt, este apoyo tuvo siempre un cierto sesgo patriarcal (o por lo menos la articulación de la niña, la musa y la poeta fue siempre ambigua). Otras razones fueron probablemente la misoginia imperante en el ámbito cultural chileno, la ruptura de la escritura winettniana con respecto a la tradición literaria mujeril, con excepción de

1 Presentación de la edición crítica de la obra poética de Winétt de Rokha (Prólogo, recopilación y notas de Javier Bello) leída en el Observatorio de Lastarria, Santiago de Chile, el 7 de agosto del 2008. 
Mistral y el hecho de que el campo literario nacional se encontraba dominado por una crítica y medios de comunicación liderados por hombres. 2. La importancia que tiene que este rescate se haga con toda la artillería pesada disponible. Es decir, creo que resulta fundamental que el campo literario sea taponado, interdicto, censurado, con la presencia de este artefacto productivo que llena uno de los tantos vacíos de un sistema, que como tantos otros, se pretende absoluto y casi objetivo. La producción de este libro entrega no solo la obra completa de una poeta fundamental en el movimiento cinemático de nuestra cultura, sino que los bombardeos críticos que la acompañan encajan sus dardos en el mesiánico sistema literario chileno y muestran una vez más sus fisuras. El texto crea de esta manera su propio movimiento envolvente entre la emisión y la recepción, una multiplicidad de supuestos, preguntas y respuestas que deben seguir siendo abordadas por un público real siempre posible.

Entrando en el espacio privativo del artefacto libro y su composición, me parece que se trata de una verdadera antología crítica y no como muchos libros al uso disfrazados de tal. En su cuidadoso mosaico hay una decisiva intervención totalizadora, aunque no total. En este sentido, quedan abiertos diversos puntos de fuga en los poemas y en las intervenciones críticas que apuntan a continuar un diálogo circundado de interrogantes, no solo en torno a la poeta, sino también al sistema literario que la borró de sus archivos. Dejando de lado ciertos detalles no menores, como la portada, la foto del encabezamiento, los agradecimientos, la dedicatoria a Julio Tagle, miembro y amigo de la familia, la presentación de las solapas y la contratapa, lo medular de esta edición crítica corresponde a un prólogo de su editor, Javier Bello, la producción completa de Luisa-Juana InésWinétt, 13 referencias críticas históricas de gran heterogeneidad, seis estudios críticos actuales, cuatro poemas de Pablo de Rokha dedicados a la poeta, algunas cartas inéditas y una interesante iconografía.

El prólogo de Javier Bello sitúa en primer término la obra de Winétt en el contexto de la poesía chilena y de la recepción crítica. Señala la falta de difusión de su producción desde la publicación de la Antología de 1953 publicada por Pablo de Rokha y la desviación biográfica que ha tenido su exigua crítica. Habría que señalar que además de las antologías mencionadas por el editor, existe una Antología de la poesía latinoamericana de vanguardia (1916-1935) de Mihai Grunfeld, publicada por Hiperión en España, en donde se seleccionan 55 autores y de ellos solo 3 son mujeres siendo una de ellas Winétt de Rokha y las otras dos: Norah Lange y Magda Portal. Winétt aparece con 8 poemas, incluyendo un fragmento de El valle pierde su atmósfera. Bello se acerca a la figura y a la producción de Winétt articulando su aproximación frente a la tradición literaria, con alusiones substanciales a los aportes de las críticas y los críticos que intervienen en la antología. Hace una descripción de la estructura de la edición y de las razones de la inclusión de cada texto. Su trabajo analítico desmitifica los modelos críticos de la tradición anterior que sirvieron para analizar la obra de Winétt, incluyendo al propio Pablo de Rokha, cuyo paternalismo era evidente, pero también contradictorio. A mi juicio, la intuición poética del vate le permite muchas veces ir más allá de la visión de Winétt como flor, diosa, musa, madre y niña, para convertirla en una poeta que se asemeja a Safo de Lesbos, a Teresa, a Juana Inés, a Delmira, a Emily Bronté como señala en Fuego negro. Javier Bello hace el recorrido de los textos en paralelo al recorrido de los nombres Luisa-Carlos versus 
Winétt-Pablo en un espejeo que reconoce el símbolo de la pareja mítica que se quiere ser en el pacto poético. Pero también llama la atención sobre la otra búsqueda, la que se inicia desde Formas del sueño y que se aleja de la representación que hace la crítica sobre su cuerpo, para llenarse con ella misma desde el puro vacío existencial. En este sentido, recoge las contribuciones críticas que aparecen en el volumen, de Monteleone, Falabella, Ortega, Valdés, Mateo del Pino, entre otros y otras, para apuntar sus diversos aportes desde una actualidad analítica que se compromete con la literatura de mujeres. El prologuista busca mostrar cómo el camino de la poeta hacia el autorreconocimiento pasa por ciertos ritos: el amor, el vacío, la muerte, la aurora, todos elementos que mutan y se transforman en un renacimiento marcado por la experimentación lingüística. Cierto desborde profético convierte a la sujeto en su propio referente, que ahora deja de ser subalterna, consorte, flor o madre enlutada, para transformarse en el propio recorrido de su escritura y asumir un lugar similar al de su marido Pablo de Rokha.

No nos detendremos mayormente en los 13 textos de la crítica tradicional, no solo por motivos de tiempo, sino también porque en gran medida repiten -con algunas excepciones- una diversidad de estereotipos sobre la poeta y su producción, ya analizada por los críticos actuales del libro. Winétt como madre, mujer y artista encantadora, niña bella, artista popular y epopéyica, mujer excepcional, reina, buena, mística, poeta del pueblo, femenina, tierna y revolucionaria, son los epítetos que se repiten hasta el cansancio en esos esbozos críticos del pasado.

Termino esta breve presentación, haciendo una breve reseña sobre los aportes de la crítica que actualiza el libro desde nuevas perspectivas teóricas, poniendo especial énfasis en el contexto histórico cultural, la recepción crítica, las relaciones familiares y maritales, las transformaciones discursivas de la poeta, la subversión del nombre y del pseudónimo, la construcción de subjetividades, las marcas identitarias, las representaciones del campo y la ciudad y el desarrollo de nuevos imaginarios, entre otros.

Soledad Falabella pone énfasis en el pseudónimo como estrategia y sus relaciones con el género, el poder y la legitimación. En su planteamiento se releva el cambio de nombre que va de Luisa Anabalón Sánderson al seudónimo de Juana Inés de la Cruz en Lo que me dijo el silencio como una negociación con las normas estatuidas, y más tarde al seudónimo de Winétt de Rokha con Cantoral para efectuar un corte radical con su vida pasada. Este último libro presentaría un doble umbral de transformación: el de la emergencia de Winétt y a partir del poema "1936", la creación de una nueva autoconstrucción que se focaliza en el corazón colectivo de las masas. Por su parte, el crítico portorriqueño Juan Gelpí trabaja sobre la relación entre Winétt de Rokha y Alfonsina Storni, poniendo especial atención a la métrica como fenómeno fronterizo y complejo, que sería un elemento caracterizador de la poesía femenina vanguardista. Su trabajo se detiene también en Cantoral, el poemario del año 1936, para llamar la atención sobre la ruptura con el mundo rural que allí se presenta y el inicio de una representación de la masificación urbana vista de una manera positiva. Ángeles Mateo del Pino se detiene exhaustivamente en el contexto histórico cultural que existe en los albores del siglo XX en Chile y América Latina, para trazar un mosaico de la situación de las mujeres dentro y fuera del ámbito de la cultura, y articularlo a la escritura de Winétt de Rokha y sus compañeras de ruta. En ese mismo impulso establece un cuadro sinóptico de la crítica 
coetánea y posterior, para luego relevar los principales tópicos, estereotipos y mitos que conformaron la recepción de los distintos libros de la poeta. Mateo del Pino también se detiene en forma meticulosa en el análisis de las diferentes máscaras y estrategias nominativas de la poeta, desplazamientos de la identidad (Juana Inés, Winétt, Luisa, Ivette, Federico, Marcel) que buscan invisibilizar el yo biográfico para relevar un yo literario que pueda existir más libremente.

El crítico argentino Jorge Monteleone se detiene en el análisis de la construcción del sujeto imaginario en la poesía wittnetiana. Su planteamiento revisa las diversas instancias de su periplo, comparando los seudónimos con los textos, así como con las transformaciones de los sujetos que los conforman. Desde Juana Inés de la Cruz, su primer paso como figura autoral, cuando la sujeto se duplica en un monodiálogo consigo misma, siguiendo los pasos de la figura monacal de su seudónimo, pasando por el vínculo yo-tú que desarrolla como Winétt de Rokha y que llena la aparición de Pablo de Rokha como alteridad del diálogo amoroso, hasta completar lo que el crítico llama "el esquema vacío de una poesía futura". En ese esquema, el vaciamiento parece estancarse en el tú como cuerpo y como mirada. A juicio del autor, la poeta encuentra dos formas de multiplicar el sujeto, siendo la primera la hermandad solidaria de la utopía socialista y la segunda, el camino de las formas del sueño, que es otro modo de aprehenderse a sí misma. La posición de la sujeto en este momento será desasirse del cuerpo para anclarse en los signos que la nombran, que la fragmentan y la multiplican en un sinfín de imágenes analógicas propias del sueño, donde lo corporal carece de presencia o se ha disgregado. Es por ello, que finalmente si el cuerpo es la metáfora del yo, la palabra se convierte en correlato de la subjetividad, un desmembramiento y un estallido del signo-palabra que se lanza al éxtasis de lo abierto.

Las dos últimas críticas del volumen son las de Eliana Ortega, que se refiere fundamentalmente al poema "Santiago ciudad" de Cantoral, y Adriana Valdés, que analiza dos reseñas críticas escritas en distintos momentos y establece su propia visión sobre la poeta. Ortega revisa la profusión del tema-símbolo ciudad en la producción de Winétt, el entusiasmo de su visión paravanguardista por las nuevas modalidades del mundo urbano y sus relaciones con el proceso de la modernidad, el voyeurismo cómplice de su mirada que se apropia del ámbito ciudad en términos de memoria y también de porvenir y la posibilidad de que la descripción externa del mundo representado sea finalmente una oportunidad de dialogar con su propio texto, escritura y espacio. Por su parte, Adriana Valdés analiza dos textos críticos, el de Manuel Magallanes Moure publicado en 1915 y el de Juan Luigi de 1951, para demostrar no tanto la falacia de sus elogios, sino la marca de los contextos y la influencia de los lugares comunes de época. Mientras Magallanes Moure celebra la "ingenuidad" y la "valentía moral" de la poeta, además de la sensibilidad, la emoción, la belleza física y la fragilidad, reglas de conducta necesarias para que una mujer escriba, Juan de Luigi se detiene en la influencia de Pablo de Rokha, las dotes femeninas de Winétt y su lealtad a la causa popular. Valdés culmina su presentación con un escorzo sobre la borradura que ejerce el yugo marital sobre la obra de Winétt y la necesidad de estudiar otras líneas de trabajo, como la mimetización de las escrituras de ambos poetas, la escritura política, el eros femenino que se vislumbra desde sus comienzos y las representaciones de la maternidad. 
Termino este somero recuento de la obra que aquí presentamos, recabando la importancia que tiene, tal como lo señalé al comienzo, para los estudios literarios y para nuestra cultura en general, dándole al nuestra el sentido colectivo que debe tener. Es un esfuerzo de investigación y divulgación realizado con rigor, con apertura de miras y un rescate cuidadoso y respetuoso de una de nuestras poetas fundamentales. Quedan aún por estudiar otros aspectos de la obra witnettiana como es lógico y obvio, entre ellos, incursionar en el trabajo estético y crítico de la poeta para vincularlo o separarlo de la producción crítica de Pablo de Rokha. En este aspecto, y dentro de la especificidad de su propia visión crítica, se encuentra la carta-manuscrito publicada en Suma y destino, dirigida al escritor polaco Witold Gombrowicz, uno de los grandes narradores del siglo $\mathrm{XX}$, en que puntualiza sus diferencias doctrinarias y estéticas con el autor europeo, así como una serie de textos publicados en la revista Multitud, en diarios y otras revistas.

Le deseo al libro un viaje fructífero y polémico, hacia, en y entre sus lectores.

Palabras Clave: Winétt de Rokha, literatura chilena, poesía, presentación de edición.

KEY WORDS: Winétt de Rokha, chilean literature, poetry, book presentation. 